\title{
Enabling local adaptation to climate change: towards collective action in Flagler Beach, Florida, USA
}

\section{Chad Stephen Boda ${ }^{1} \cdot$ Anne Jerneck ${ }^{1}$}

Received: 5 December 2018 / Accepted: 11 November 2019/Published online: 30 November 2019

(C) The Author(s) 2019

\begin{abstract}
Local communities around the world are directly exposed to impacts of climate change. It is also clear that many local governments are politically and economically constrained in their capacity to implement needed adaptations. These constraints can restrict adaptation options to incremental, or even maladaptive, practices. At the same time, necessary transformational actions may remain out of reach for local actors. Building on five years of collaborative research with the city of Flagler Beach (FL, USA), we draw on political process theories to describe how incremental adaptation activities that are possible within current constraints can serve to build local capacity for instigating reforms at higher scales of social organization. We use the concept of a collective action strategy to conceptualize how context-specific barriers to adaptation can be overcome. From our analysis, an idealized multi-step process for designing collective action strategies is presented. The study advances scholarship on limits to adaptation beyond the diagnosis of barriers to action by taking steps towards developing context-specific strategies for overcoming these barriers.
\end{abstract}

Keywords Scale $\cdot$ Barriers to adaptation - Incremental adaptation · Transformational adaptation · Social change $\cdot$ Strategy

\section{Introduction}

Local communities in the USA and around the world are directly exposed to the physical impacts of climate change (CC) (USGCRP 2018; Masson-Delmotte et al. 2018). Yet, many local governments are highly constrained in their capacity to adapt to these impacts. These constraints include limited access to financial and other resources, as well as limited authority over geographic areas where adaptation is most needed. Such constraints can confine local government's capacity for adaptation to incremental or even maladaptive practices when more

Chad Stephen Boda

chad.boda@lucsus.lu.se

1 Lund University Center for Sustainability Studies, Lund, Sweden 
transformational adaptation approaches remain out of reach (Magnan et al. 2016). In many places, the easing of existing constraints is likely to be necessary to enable transformative adaptation to CC at the local scale (Runhaar et al. 2018). Failure to adapt to CC may result in loss and damage to communities and ecosystems, ultimately undermining sustainable development (Warner and van der Geest 2013). However, overcoming financial and legal constraints on local adaptation may require instigating changes further up the administrative hierarchy.

In this article, we present findings from a five-year study of critical erosion management in the coastal city of Flagler Beach, FL, USA. In the face of worsening beach erosion, local government and residents in Flagler Beach have been confined to a limited set of incremental adaptations, largely due to budgetary and administrative constraints. These incremental activities are in isolation insufficient to address the city's most serious adaptation problems. At the same time, state actors have continued to promote maladaptive alternatives to manage critical erosion in the city (see Boda 2018a). We draw on political process theories to argue that currently possible incremental adaptations can be strategically used to cultivate capacity for collective action capable of instigating policy changes at higher administrative levels. Such changes have the potential to enable transformative adaptations at the local level that are currently out of reach.

We begin by outlining how we understand local CC adaptation and how this understanding relates to the wider field of adaptation studies. We then introduce the concept of a collective action strategy, clarifying what role incremental and transformative adaptive actions can play in a long-term pathway to social change. After introducing the case and methods, we synthesize research outcomes in the discussion section and summarize our findings. From this, we present a generalized multi-step process that can help guide the design of collective action strategies fit-for-context. We conclude with some remarks on the implications that our study has in the wider context of cultural, institutional, and financial barriers to $\mathrm{CC}$ adaptation.

\section{Local adaptation and the paradox of scale}

IPCC defines CC adaptation as "adjustment in natural or human systems in response to actual or expected climate stimuli or their effects, which moderates harm or exploits beneficial opportunities" (Parry et al. 2007). In parallel to mitigation, adaptation is widely recognized as one of two main response options to reduce the risks associated with $\mathrm{CC}$. Adaptation is fundamentally about the ability of systems, communities, and individuals to cope with multiscalar processes of change (Dodman and Mitlin 2013). As such, adaptation should not be informed only by bio-physical knowledge, but also by insights on economic, political, and socio-technological conditions and interactions (Khan and Roberts 2013). Adaptation should seek to reduce exposure and vulnerability while also increasing capacity to resist or recover from the potential adverse impacts of CC (Field et al. 2012).

Given historic and current emissions, some degree of adaptation to $\mathrm{CC}$ are unavoidable, not least along densely populated coastlines that will be affected by sea level rise, increased storm surge, and accelerated erosion (Pachauri et al. 2014). However, research has consistently shown that local communities can be significantly constrained in their decision-making capabilities. Restrictions may be imposed by legal, economic, and other social structures at higher scales of social organization (Moser and Ekstrom 2010; Measham et al. 2011; Amundsen et al. 2010) that become compounded at the local scale. Murawski (2007, p. 
687) dubbed this concentration of administrative burden the "paradox of scale," meaning the "smaller the spatial resolution, the larger the number of institutional entities that may potentially be involved in decision-making." Importantly, the hierarchical nature of many environmental management institutions (see Hägerstrand 2001) means that this paradox of scale can make local adaptation efforts significantly more cumbersome to design and challenging to implement. In extreme cases, higher-level constraints can completely thwart local adaptation efforts, as seen in certain US states where regulatory structures and counter-incentives make coastal adaptation practically impossible (McGuire 2018). Effective action on the ground may very well rely on adjusting or reforming existing conditions to alleviate higher-level constraints and facilitate the funding, design, and implementation of adequate adaptation efforts.

In theory, there are two principally different types of adaptation, namely incremental and transformative. These can be thought of as laying on a continuum, from more additive and short-term to more transformational and long-term processes of change rather than a mutuallyexclusive dichotomy (Pelling 2010; Feola 2015; Termeer et al. 2017). There are however real and significant qualitative differences between them (Mahoney and Thelen 2009). Incremental adaptation primarily serves to maintain a current system or process, while transformative adaptations aim to make more fundamental changes in system attributes. There is a risk of reaching limits to incremental adaptation, especially in places that are extremely exposed to CC impacts (Warner and van der Geest 2013). In such places, transformation, rather than only adjustment, should be a main purpose of adaptation (Noble et al. 2014). Indeed, many adaptation that scholars have emphasized the need to focus more on the underlying social drivers of vulnerability (Pelling and Manuel-Navarrete 2011; Ribot 2011), and to view adaptation actions as profound, transformational political-economic change (Bassett and Fogelman 2013). However, calls for major structural transformations remain vague without identifying what viable agent and through which particular processes such changes can be accomplished (Termeer et al. 2017). Much adaptation research has focused more on intentions to act and less on actually existing adaptations (Berrang-Ford et al. 2011). This leaves a gap in understanding regarding how transformational adaptation can be practically attained, and what role incremental actions can play in achieving more transformational goals.

\subsection{Adaptation and collective action}

There is potential for incremental actions and transformational aspirations to be connected through what we here termed a collective action strategy for local adaptation. Put simply, a collective action strategy is a long-term plan of political action that views incremental adaptation activities as a means to build capacity for collective action towards transformative adaptation in the future. We thus join others in advocating an approach to $\mathrm{CC}$ adaptation that views incremental and transformational actions not as mutually exclusive, but as inherently related in theory and practice (Termeer et al. 2017; Park et al. 2012).

Collective action occurs when individuals come together and coordinate their efforts on behalf of shared interests or programs (Tilly 2008, p. 6). Our conceptualization of a collective action strategy, as a form of "political process" (Tarrow 2011), is grounded in the idea that social structures have micro-foundations. We recognize that individual agents may be constrained by social structures, but equally that collective agency has the potential to transform these structures. That is, "micro-structures of social relations constitute social action and force macro-structures to adapt" (Della Porta and Diani 2015, p. 44). Furthermore, while some structural transformations may be objectively necessary, they will not take place without 
the intentional, strategic intervention of collectively acting individuals. A social group that currently lacks needed decision-making capabilities or resources can use existing means to cultivate its collective capacity to advocate for social changes. The successful easing of hierarchical constraints, in turn, can work to broaden the realm of possible actions of the group or individual. Thus, one can think of the interaction of macro-structures and individuals acting collectively as potentially forming a virtuous circle of ever broadening possibilities for addressing adaptation needs at the local level.

\subsubsection{Internal and external capacity}

Both the internal dynamics of a group and their broader context are relevant to understanding a collective action. The relationship between a group's internal capacity to act and its external opportunities to do so will shape the possibilities for and effectiveness of collective action in politics (see Tarrow 2011). Social movement scholar Charles Tilly $(1977,2008)$ has identified key dimensions underpinning these internal and external capacities. A groups' internal capacity to collectively act has to do with qualities the group itself possesses. These involve three aspects. First, interests refer to the shared benefits or dis-benefits likely to accrue to a group as a consequence of its interactions with other actors. Second, organization involves the extent of common identity and unifying structure in a group. Third, mobilization involves to what extent various resources are under the collective control of a group. The degree to which a group holds common interests, how well organized it is, and whether mobilization actually occurs can vary significantly from one place to another. This means that the capacity for a group to collectively act must be assessed and not assumed. For example, a group with strongly shared interests may not be able to effectively act if they are unorganized or if they lack access to resources. Importantly, these criteria are not static; rather, they can be actively improved or degraded from within or outside the group in question.

A group's external capacity to collectively act has to do with the social, cultural, and political setting within which a group hopes to have influence. This involves three further features. The first, repression/facilitation, refers to those external factors that either raise (repression) or lower (facilitation) the costs of collective action. The second, opportunity/ threat, refers to the degree to which targeted actors are susceptible to demands for change. Opportunities increase the likelihood of a group's goals being achieved, while threats make this less likely. The third, power, refers to the extent to which the outcomes of the group's interactions with other actors favor its interests over those of others. The more power a group has, the more favorable interactions with other actors will be for the group's interests, while a loss of power will lead to less favorable outcomes.

In reference to local adaptation in particular, enhancing internal capacity may be closely related, but not limited, to incremental adaptations. Incremental activities can, for example, work to improve awareness of the context-specific adaptation issues, help identify common interests among local actors, and support stock-taking of the financial and other resources currently available for mobilization (Westley et al. 2013). However, certain internal capacities, most notably issues of resource mobilization, are also closely linked to the external context and related repression/facilitation and opportunities/threats afforded by hierarchical institutions. Improving internal capacity to act collectively may be further enhanced through adjustments to the external context, for example, reforming policies which dictate patterns of resource distribution. This is in line with Termeer et al.'s (2017) conclusion that "governing transformational change... requires transformation of the governance systems themselves." 


\section{Study area}

We here build on the result of Boda's five-year (January 2013-April 2018) collaborative research with the coastal city of Flagler Beach (see Boda 2018a). Flagler Beach is a city of roughly 4500 permanent residents located in Flagler County along the northeast Atlantic coast of FL, USA. This area has historically been exposed to a variety of climate-related hazards. Most notable are flooding and erosion caused in the short term by tropical cyclones and in the long term by rising relative sea level (USGCRP 2018). Flagler Beach has long struggled with critical erosion threatening local infrastructure and beach habitat (Fig. 1). Among the most vulnerable and heavily maintained infrastructure in the city is the coastal state road (SR) A1A. It is widely considered to be an essential corridor for maintaining both economic activity and public safety (e.g., emergency evacuation, see Boda 2017a, 2018c). As a result, the Florida Department of Transportation (FDOT) is the most influential actor in the practical management of Flagler Beach's local beach environment (Boda 2015). Critical erosion in Flagler Beach has progressively worsened since systematic measurements began in the late 1980s (Florida Department of Environmental Protection 2019). To make matters worse, the city's already critical situation was exacerbated when it was heavily damaged by hurricanes Matthew (2016) and Irma (2017). These two storms alone collectively increased the number of critically eroded sections from three to five, and the length of critically eroded shoreline from 4.8 to 6.8 miles of the county's 18 total miles of coastline (Florida Department of Environmental Protection 2019).

As erosion has worsened, social consensus on the need for and content of a CC adaptation strategy for Flagler Beach has remained elusive (Boda 2018d). In the face of rising sea levels, the situation is only likely to become more dire in the absence of effective adaptation. Mismatches between preferred adaptation strategies at local, county, state, and

\section{Florida}

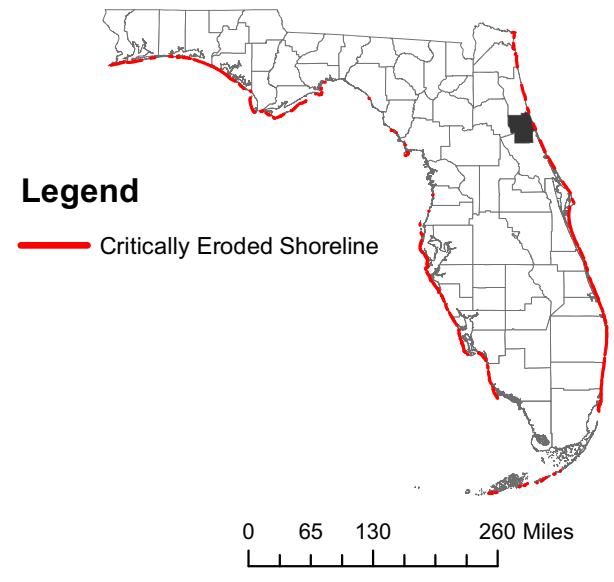

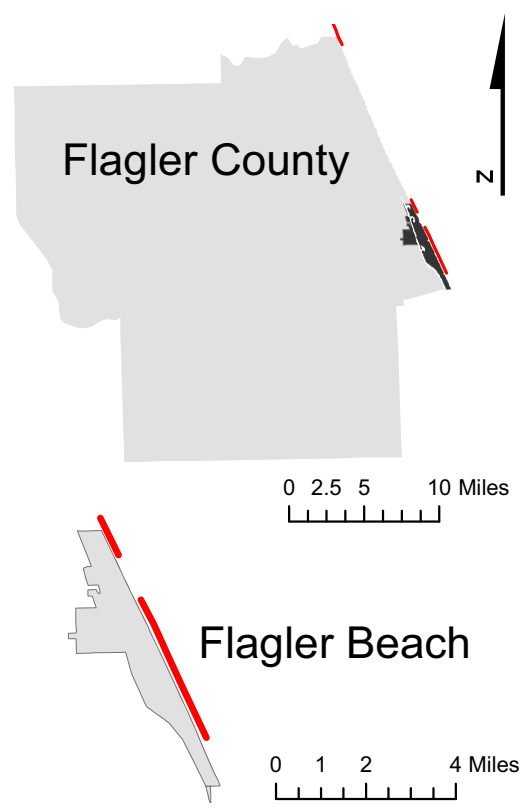

Fig. 1 Critically eroded shoreline in Flagler Beach, FL. Source: Florida Department of Environmental Protection Geospatial Open Data 
federal scales have created much frustration and discontent among elected officials and residents in the city (Boda 2015). Furthermore, there is fragmentation in community opinion regarding which beach management issues should be prioritized by the city itself (Boda 2018b, d). Under current conditions, the adaptive actions available to local government and citizens in Flagler Beach are very limited. At the same time, erosion management strategies that have been implemented or promoted by state and federal agencies have proven maladaptive or are practically out of reach for local government (Boda 2018a).

\section{Methodology and methods}

Boda's (2018a) research in Flagler Beach took as a starting point of the city's existing goals and practices regarding $\mathrm{CC}$ adaptation and coastal management. From this, the research proceeded to identify gaps, inadequacies, limits, and silences of these current goals and practices in relation to the social-environmental problems in the city. This then provided a platform for working with management practitioners to formulate more adequate goals and practices for the city. These systematically arose from attempts to correct the theoretical and practical tensions uncovered in the analysis of current goals and practices (for more on the methodology of immanent critique, see Boda and Faran 2018). Throughout the research process, a range of methods was used to generate primary and secondary data related to the socio-cultural, economic, and bio-physical characteristics of the case.

The idealized research protocol included (1) collection and analysis of contemporary public documents in Flagler Beach and Flagler County, including comprehensive plans, government budgets, recent city and county commission meeting minutes, and relevant resolutions and ordinances; (2) collection and analysis of historical archival sources, including inter alia old photographs of the city's development, documented trends in land-use change, and historic city minute meetings. In addition to public archives, historical data was collected at two local historical societies, the Flagler Beach Historical Museum in Flagler Beach, and the Flagler County Historical Society in Bunnell; (3) purposive key informant interviews (10 total) with formal beach management decision makers at city and county levels, including city mayor, city and county commissioners, city/county managers, disaster recovery experts, engineers, public safety officers, and directors of public works; (4) public opinion survey with Flagler Beach residents (see appendix 1 in Boda 2018a for description of methodology); (5) vegetation cover sampling of local vegetation for baseline date for restoration planning (see appendix 2 in Boda 2018a for description of methodology).

When implementing this idealized process, explicit efforts were made to maintain reflexivity (Alvesson and Sköldberg 2017) within and between research steps, as well as between the researcher and the relevant actors in the study context. This allowed for methodological flexibility and the continuous adjustment of scientific theorizing in relation to the ever changing empirical context (see Boda 2018b). Some data and related collection methods, such as the public survey and vegetation sampling, were adopted in response to gaps identified in the process of analyzing the empirical material collected through the first three methods. Other knowledge gaps, such as the incorporation of SLR projections into the city's beach management plans (see section 5.1), were likewise identified in this way. 


\section{Analysis and results}

Following our discussion of adaptation and collective action in section 2, we categorize research outcomes in relation to incremental and transformational adaptation needs, as well as internal and external capacities. In section 6 below, we will discuss how these different kinds of adaptation and collective agency can be incorporated into a broader strategy for social change.

\subsection{Incremental adaptations}

In Flagler Beach, a variety of incremental adaptations were formally established through the community-based work of the Beach Management Ad Hoc Committee, which over the course of 2 years had produced the city's Beach Management Plan (BMP) (Beach Management Ad Hoc Committee 2014). The BMP included specific recommendations for incremental improvements in the city's beach management practices. These include the following: (1) enforce existing laws and ordinances; (2) education; (3) monitor and clean the environment; (4) buildup the natural dune structure; (5) outreach; (6) public access and safety. In collaboration with local environmental managers, these recommendations for incremental changes were operationalized through four major activities.

A. Assessing community awareness and engagement in beach management - addressing recommendations $1,2,3$, and 5

This resulted in a public survey, summarized in a policy report, and utilized for public outreach planning and selection of appropriate communication techniques. Survey outcomes were also shared with the community in a public awareness workshop that took place at Flagler Beach City Hall on October 27, 2016 (Simmons 2016).

B. Beach cleaning App—addressing recommendations 1, 2, 3, 5

Utilizing an established, periodic community activity, specifically a monthly, voluntary beach cleanup organized by the city mayor (see FlaglerLive 2016a), we developed an interactive non-native trash collection App with limited functions. The purpose behind the App, which was originally suggested by local environmental managers, was to encourage awareness raising and sustained participation in local pollution reduction, e.g., by allowing participants to track the type and quantity of trash collected over-time. The information collected through the App was also intended to provide empirical evidence to support the city's efforts to obtain financial and logistical backing from county and state agencies regarding pollution reduction. While local pollution is not necessarily directly related to $\mathrm{CC}$, it is among the main priorities of local government and citizens in relation to maintaining a healthy beach environment.

C. Revegetation and erosion control—addressing recommendations 3, 4, 6

In collaboration with city environmental managers, Boda conducted a field-based survey of dune plant cover and type in critically eroded areas of Flagler Beach. This resulted in a policy report that is at the time of writing being used to inform the development of a communitybased dune revegetation project (Anderson 2017). 


\section{Planning for sea level rise-addressing recommendations $2,4,5,6$}

In dialog with local practitioners, the need for the incorporation of an academic review of SLR science and specific threats to Flagler Beach was identified and carried out. The results were summarized into a policy report that was then presented at a public workshop (Ryan 2018). The policy recommendations related to SLR are being incorporated into the revised BMP, which is being updated by the re-instated Beach Management Ad Hoc Committee in the hopes of securing financial support for beach management from the Florida Department of Environmental Protection (FlaglerLive 2018b; see section 6.2 below).

As we will argue in the discussion (see section 6.2), these incremental activities have potential to address some local environmental problems while simultaneously contributing to the development of the community's collective agency. However, these incremental activities also suffer from serious limitations. Some of these activities do not address the root of the most pressing problems in the city. For example, assessing community awareness and making a beach cleanup App do not directly address the most pressing problem of critical erosion. Other activities face constraints that are beyond Flagler Beach's own capabilities to effectively implement. For example, as we will see in the following section, the community is severely limited in its ability to implement revegetation projects and plans to avoid the impacts of sea level rise. While all the activities are important, the first two are inherently limited in their reach, while the latter two are limited by external conditions. We turn next to these barriers to transformational adaptation in Flagler Beach.

\subsection{Barriers to transformational adaptation}

Attempts to operationalize some incremental adaptation goals, in particular revegetation and planning for sea level rise, have exposed structural limitations on the city's ability to manage its local environment. We discuss in particular political and economic constraints, each posing particular challenges to local action. Of course, the specific structural constraints encountered in this research are context-specific, and constraints may differ between contexts. Likewise, the biophysical constraints relevant to the case are a contingent feature of case geography. For example, biophysical constraints in Flagler Beach are related to the dynamic processes of barrier island bio-geomorphology that limit the kinds of technology which can be considered ecologically sound (see Boda 2018a, p. 126-142). While an understanding of biophysical constraints are central to effective adaptation, we here focus primarily on constraints stemming from the social context, as these are amenable to transformation through individual and collective action in a way biophysical limits are not (Adger et al. 2009).

\subsubsection{Political constraints}

The first of the major constraints experienced in Flagler Beach is related to the political geography of environmental management in the state of Florida. Generally, environmental management institutions in the USA are characterized by a hierarchical system of nested spatial domains, with lower-scale domains beholden to the rules and regulations of the higherscale domains (see Hägerstrand 2001). As mentioned in the case introduction, the FDOT has been the dominant agency in critical erosion management in Flagler Beach due to the historic placement of coastal SR A1A. This same critical erosion has been the focus of, e.g., the abovementioned revegetation efforts. However, such local efforts have generally been 
frustrated by FDOT priorities and practices (Boda 2015). The FDOT's power to act at the local scale is derived from, and bounded by, its legal right-of-way, a spatial domain specific to the production and maintenance of transportation systems. Within this right-of-way, the FDOT has formal legal authority established under Florida Statutes 334.044 (14). The FDOT's right-ofway gives the agency a form of power that Hägerstrand and Clark (1998, p. 21) termed territorial competence. This concept captures the idea that physical actions in the landscape are "always effectuated by some primary actor... whose rights are protected by law... but at the same time also strictly limited in space by the same rule systems." As a result, the FDOT and its commitments remain the decisive factor in addressing the city's critical erosion problems (Boda 2015).

The major problem arising from this hierarchical situation is related to the FDOT's commitment to keeping SR A1A in its current location, despite increasing critical erosion and sea level rise projections. The continued maintenance of SR A1A through seawalls and rock revetments has proven maladaptive, both increasing critical erosion in the city over time and leading to detrimental impacts on nesting habitat of endangered sea turtle species (Boda 2017b; Boda 2018c). Due to both environmental and economic concerns (e.g., Flagler Beach relies heavily on beach-based tourism, see Boda 2018a, p. 160-163), the city itself has long resisted the FDOT's promotion of sea walls, even passing a formal resolution opposing the FDOT's plans in 2011 (Resolution 2011-15). Regardless of local resistance, the context's political hierarchy allows the FDOT to continue to pursue maladaptive forms of coastal erosion management, in particular, the construction of vertical seawalls. In the last year alone, the length of concrete sea wall within municipal boundaries has grown from around $150 \mathrm{ft}$ to nearly 2 miles as a result of FDOT activity (FlaglerLive 2018a; Boda 2019).

While the FDOT is the major culprit, other political challenges also exist. State agencies such as the Florida Department of Environmental Protection and federal agencies such as the Army Corps of Engineers also constrain local actions through, for example, strict coastal construction permitting requirements (Boda 2015). Adding to these social constraints, the scalar structuration of barrier island bio-geomorphic processes also sets boundaries on the possibilities of local governments to manage erosion in Flagler Beach (see Boda 2018a, p. 125-142). This is because the mechanisms driving many significant barrier island morphological processes, such as sand supply and transport, operate at spatial scales which may stretch far beyond local municipal boundaries and thus out of the spatial domains where city officials hold territorial competence (Oost et al. 2012). The cross-boundary nature of many coastal processes necessitates integrative governance strategies that coordinate the activities of various actors, policies, and natural processes within and across scales (Feagin et al. 2010). It has long been argued that effective integrative governance relies on the active engagement of all relevant actors and their shared commitment to adjusting policies to better fit the social and ecological context (Ehler and Basta 1993). Florida's coastal management programs, however, have long been plagued by a lack of government consensus and weak incentives to promote cross-scale coordination, leading to fragmented, piecemeal, and often ineffective implementation of conservation policies at the local level (Guy 1983; Brody and Highfield 2005).

\subsubsection{Economic constraints}

The structure of Florida's public revenue system also imposes serious constraints on the municipal-scale capacity to collect public funds for environmental management (Nicholas et al. 2007, p. 55, Boda 2018c). These restrictions include the following: property tax 
constraints, such as legal limits on allowable property tax rates and homestead tax exemptions that waive certain property tax obligations for permanent residents; sales tax constraints, such as limitations on use of sales tax revenues and the requirement of voter approval for leveeing new sales taxes; and income tax constraints, which both state and local governments are constitutionally prohibited from collecting (MacManus et al. 2008, p. 317-320). When sales tax is collected by local governments in Florida, they are legally obligated to seek approval from the Attorney General before they can spend it on beach management. Flagler Beach was granted permission to allocate local sales tax to beach management in 2012 (FlaglerLive 2012). However, without expanding revenues, the city has been unable to allocate consistent funds for this purpose. Instead, the city is heavily reliant on the state to fund critical erosion management, and these resources are largely under the control of the FDOT. For example, the average annual maintenance costs for the largest eroding section of state-funded SR A1A between 2000 and 2010 had been around 1.25 million USD, which is nearly four times the annual amount allocated to local tranportation in the city's budget (see Boda 2018a, p. 98106). Relocation of this 5.2-mile sections of road has been estimated to cost anywhere between 4.7 and 43.2 million USD per mile depending on the specific project details (FlaglerLive 2016d). These costs would likely surpass the financial capacities of most Florida cities the size of Flagler Beach. Indeed, across the state, these constraints on revenue collection have affected local governments' ability to acquire financial resources sufficient to effectively manage environmental problems that have come as a result of the state's historically rapid pace of growth and development (Pelham 2007, p.17).

The financial limits of the city's ability to adapt to its critical erosion problem were most obvious in the aftermath of Hurricane Matthew in early October, 2016. The storm caused an estimated 60 million USD in damage to the county's beaches alone (FlaglerLive 2016b). The cost of repairing a 1.3-mile section of SR A1A in Flagler Beach which was badly damaged in the storm was initially estimated at anywhere between 10 and 222 million USD, depending on the specifics of the selected repair project (FlaglerLive 2016c). For comparison, Flagler Beach's total expenditures in 2014 amounted to just over 4 million USD (Boda 2018a, p. 102-103). Indeed, Hurricane Matthew all but completely eliminated the ability of city government to fund response and recovery from coastal storms, let alone engage in proactive adaptation. As a local newspaper commented in early 2017, nearly 6 months after the storm, city and county government "literally cannot afford another severe storm striking its territory: it would most likely not have the money to recover, absent greater intervention from state and federal sources" (FlaglerLive 2017a). This mirrors a shrinking disaster recovery fund at the state level (FlaglerLive 2017b).

\section{Discussion}

As we have seen, existing economic and political barriers limit potential adaptations in Flagler Beach to either incremental activities with limited impact, or to the maladaptive strategy adopted by the FDOT. Achieving transformational adaptation in the city, for example, relocation of vulnerable infrastructure and large-scale ecosystem restoration, would require the removal of these barriers. If they persist, current policies and commitments at the FDOT will ensure the further expansion of seawalls in the city as critical erosion worsens (Boda 2015). Such an outcome is troubling in the context of the wider trend in the USA of concretization of the country's coastlines. In absence of substantial policy changes, sea level 
rise will contribute to the percentage of concretized shoreline doubling from 14 to nearly $30 \%$ by 2030 (Gittman et al. 2015). Current economic constraints will also continue to lead to maladaptive practices in Flagler Beach and elsewhere. Limits on sources of public revenue provide a strong incentive for local governments to approve urban development projects (e.g., housing) as a means to expand the city's tax base. However, much of the undeveloped land in Flagler Beach is extremely vulnerable to flooding from sea level rise and storm surge, some of which is already approved for future development. Developing this land will only exacerbate vulnerability and increase the urgency of local adaptation. Indeed, the precarious position of some communities may necessitate managed retreat as the only practical option to adapt to climate-induced changes to the coastal environment (Siders et al. 2019; Kousky 2014). Despite these worrisome prospects, comprehensive reviews have shown that the majority of land vulnerable to sea level rise along the US Atlantic coast is planned to be urbanized by local governments (Titus et al. 2009).

We have argued thus far that achieving transformative adaptation may require removing administrative and financial barriers at higher scales of social organization. We have also argued that the development of a collective action strategy for enabling local adaptation has the potential to support the removal of such barriers and facilitate more transformative change. A collective action strategy which relates incremental adaptations to transformative needs would rely on two main features, (1) intentionally aiming to remove current constraints to enable more transformative local adaptation, and (2) understanding ongoing incremental adaptation activities as potential means to increase capacity for collective action, rather than as isolated efforts.

\subsection{Removing constraints to enable transformative adaptation}

If a local community is not constrained in its adaptation abilities, then there may be no need to transform current structures. However, many places, as in the case of Flagler Beach, are in fact significantly constrained. Among the most significant obstacles faced by Flagler Beach is its lack of power to decide how coastal erosion will be managed at the local level. It is also extremely limited in its financial capabilities to implement and maintain erosion control strategies. In absence of major changes to state public revenue and environmental management policies, the financial barrier in particular will become increasingly severe as sea levels rise and thus erosion continue, raising the material and labor costs of beach maintenance over-time (Boda 2018a, Chapter 7). These existing constraints must be removed to facilitate more transformative social change.

If Flagler Beach is going to have more say in how its local beach environment is managed, including strategies for adaptation, it must advocate for adjustments in governance structure higher up the administrative ladder. Regarding political constraints, changes at the state level are primarily needed if local government's role in decision-making is to be expanded. The removal of constraints can be accomplished in various ways, including, inter alia, making changes to current agency priorities that incentivize maladaptive practices, and increasing institutional support (e.g., permitting and knowledge sharing) from higher scale agencies responsible for coastal management. Regarding economic constraints, the city must advocate for changes at state and federal levels that facilitate increased flows of public funds for adaptation projects. This could involve either the re-direction of existing funds, or mechanisms for the collection of new funds sufficient to design, implement, and monitor transformational adaptation projects. 
To date, advocacy efforts in Flagler Beach have been limited and sporadic. The most notable instance of concerted advocacy involves the city hiring the K Street firm Marlowe and Company to formally lobby for beach nourishment funding at the federal level (Boda 2018a, p. 203). Advocacy, however, can take a wide variety of forms, ranging from petitions to lawsuits, from sanctioned festive street demonstrations to strategic acts of civil disobedience. Flagler Beach has on occasion witnessed, for example, citizen-organized marches to raise awareness of the problem of climate change (FlaglerLive 2017c). Which advocacy tactic is most appropriate and when can only be answered in relation to the concrete aims and internal capacities of a specific group, as well as what political opportunities or threats they face. What is more likely is that a combination of various advocacy actions will be needed (McAlevey 2016). This could include, for example, simultaneously pressuring government representatives to champion the adaptation cause, linking local concerns with growing international climate change protests and advocacy campaigns, and engaging in strategic litigation. When these advocacy activities are well organized, coordinated, and sustained, they can form the basis for a social movement with the power to instigate significant and lasting change (Tilly and Wood 2015).

The goal of advocacy is not to completely localize decision-making, as it is clear that the financial and administrative burden of large-scale coastal adaptation is likely to be beyond the capabilities (and some would say responsibilities) of many local governments (Purcell and Brown 2005; Cooper and McKenna 2008). The goal instead is to instigate more integrative approaches to coastal management capable of addressing adaptation needs across scales. Removing economic and political constraints and instigating productive cross-boundary coordination will likely require connecting local efforts to other communities with shared interests. Within Flagler Beach, however, there is a disagreement among residents and elected officials regarding perceived interests and priorities for coastal management in the city (section 3 ). Such tensions complicate mutual agreement on shared interests and goals, and reduce the community's ability to organize effectively around the adaptation issue (Boda 2018a, p. 225231). Building internal capacity in Flagler Beach would thus involve the development of mutual understanding, common interests, and identity, as well as agreeing upon a group structure conducive to sustained participation in collective action by both residents and elected officials. Flagler Beach is not currently engaged in regional networks for adaptation to CC. However, good examples in the Florida context exist which show that collective action between municipal governments is feasible and even effective at overcoming certain kinds of administrative and financial constraints at the municipal scale. Most notably is the Southeast Florida Regional Climate Change Compact. This CC-focused organization was formed through a collective action among county and city governments to support local adaptation practices in South Florida, despite a generally constrained and repressive external context (Vella et al. 2016).

\subsection{Incremental adaptation for collective action}

Removing structural constraints on local adaptation may require collective action to instigate needed changes to political and economic policies and practices. However, the possibility of transforming structural constraints is related to internal and external capacity for collective action, which may need to be cultivated (see section 2.1.1). While incremental adaptation can help address certain important and immediate problems in the local context, it does not suggest big changes to structures and often is incapable of directly changing constraining structures. 
When viewed solely in this isolated light, incremental adaptations can seem utterly inadequate in the face of current and projected climate impacts. However, there is potential for incremental changes to be used as a means to sensitize citizens and environmental managers to the limitations imposed on local communities.

Incremental activities like those being undertaken in Flagler Beach can serve to educate citizens about their stake in the adaptation issue, and to develop a network of solidarity based on citizens' common interests in adapting. This in turn promotes internal capacity to organize and mobilize around common interests. For example, activities such as community trash collection, informational outreach, and community-run revegetation projects all have the potential to allow community members to develop an understanding of their interest in local environmental problems, to encourage local organization, and to support political mobilization when promising opportunities arise. Empirical evidence linking voluntary participation in local projects to participation in related political processes (e.g., Walker 2008) supports the claim that practical engagement of citizens in incremental actions can provide a pathway to political mobilization. It has however been argued that such psychological factors can pose serious barriers that may prevent individuals from accepting and participating in $\mathrm{CC}$ adaptation (Gifford 2011). The cumulative outcomes from incremental adaptations may be crucial to addressing such psychological barriers, as they have the potential to contribute to awareness, the formation of common interests, strengthening organization, and lowering the costs of mobilizing people and resources.

Likewise, the practical outcomes of incremental activities can be geared towards enhancing the external capacity for action, in particular, using existing mechanisms to improve local access to needed financial and other resources. This is the case, for example, with Flagler Beach's current redevelopment of its BMP. The city reinstated its Beach Management Ad Hoc committee, utilizing outcomes from this research, with the aim to secure a consistent flow of beach management funds from the Florida Department of Environmental Protection's coastal stewardship grant program (FlaglerLive 2018b). Other external factors are beyond the control of local collective action, such as the timing of storms or shifts in political power and priorities at state and federal levels. As a result, Tarrow (2011) and others point out that movements need to be ready to take advantage of moments of political opportunity when they arise. Such opportunities can come as a result of changes in governing administration or physical context (e.g., post-disaster). This temporal uncertainty highlights the importance of developing and maintaining internal capacity so moments of political opportunity can be exploited.

There has recently been some indication that political opportunities may be on the horizon. Over the last decade, Florida climate policy has been stifled through the efforts of a largely skeptical, even openly hostile, Republican leadership (Boda 2018c). Former governor Rick Scott, infamous for banning the term climate change from his administration's official lexicon, is probably the most well-known example. However, recently, there have been indications that the tide may be changing, with some Florida GOP representatives, such as state Senator Tom Lee, bemoaning the decade "lost" to climate denial in the state (Stieb 2019). Achieving a climate-friendly policy environment in Florida, however, will still be a major uphill battle. The state is currently represented federally by Senators Rick Scott and Marco Rubio, both well known for their climate denialism. Florida also recently elected Republican Ron DeSantis as governor, who has aligned himself along party lines when it comes to environmental issues. Similarly, Flagler County's current representative, state Senator Travis Hutson, continues to push now well-trodden talking points on the futility of acting without concomitant agreement by China and India to reduce their emissions. The point is not to sit around and wait for a better 
political context to emerge, but to take advantage of shifting opinion in government representatives and the public at large to further advance and institutionalize the cause of transformative adaptation.

\subsection{Towards a collective action strategy for climate change adaptation}

From our analysis of the Flagler Beach case above, we summarize our findings in the form of a four-step idealized research process that can inform the design of a context-based collective action strategy. Each of the steps corresponds with essential information related to local adaptation needs; constraints on local action; internal and external capacity for collective action; and the combination of these into the collective action strategy itself.

The first step is to identify local adaptation needs, as covered in section 5.1 above. This involves both taking stock of people, habitats, and infrastructure that are exposed to climaterelated hazards, as well as why and how these exposed features matter to the local context (see Tschakert et al. 2017). For example, it is clearly important to recognize that a coastal road like SR A1A may be vulnerable to erosion caused by storms and sea level rise. However, it is equally important to understand the significance of the said road in the local community context, e.g., in terms of economy, safety, and cultural-historical significance. These reasons for valuing vulnerable community assets help inform which kinds of adaptation (i.e., incremental or transformative) are deemed necessary or desirable, and which should take priority when multiple adaption pathways are possible.

The second step is to identify constraints on achieving the identified adaptation needs. Barriers to incremental adaptation (e.g., psychological barriers) are of course important and where present should be identified and addressed. One example of such a barrier would be insufficient knowledge of the climate-related challenges facing a given community. We have however emphasize in particular the importance of identifying structural constraints on transformational adaptation stemming from political hierarchies, as covered in section 5.2. Such constraints are associated with particular policies and agency priorities that limit the availability of resources and the extent of local authority. Overcoming these constraints will require political pressure from collectively acting individuals to force adjustments in policies and priorities at higher scales of social organization.

The third step is to assess the local community's capacity for collective action. We have drawn on political process theories (see section 2.1) to argue that collective agency is a factor of characteristics both internal and external to a given social group. Furthermore, we have argued that internal and external characteristics are in many ways intertwined. For example, an external shock (e.g., natural disaster) may create a political opportunity which leads to an increase in the availability of resources to be mobilized by a given community, thus increasing their internal capacity as well. It is thus important that internal capacity is cultivated and maintained over time. This is because meaningful opportunities or threats are temporally uncertain, and local communities need to be able to mobilize and utilize such opportunities (or avoid threats) when they do arise.

Finally, these three steps can be combined to design a collective action strategy fit for context. Local adaptation needs have at this point been identified, as have the constraints preventing the realization of these needs in the local context. This knowledge helps clarify which specific policies, at which level of social organization (e.g., county, state, federal) needs to change. This also helps clarify which actors (e.g., state agencies or elected representatives) are responsible for these policies, and thus which specific agencies or actors a collective action 
campaign should aim to influence. These policies and related actors become, in the language of social movement theory, the "targets" for collective action, that is, to whom the demands for change are directed. Once the target for reforms has been identified, internal and external capacity can be assessed in relation to these aims. This further helps clarify in what ways capacity for action may need to be developed, and whether alliances with other communities or organizations will be necessary to achieve desired reforms.

\section{Conclusions}

In this article, we have argued that incremental adaptations can lay the groundwork for more transformative adaptations in the future. Generally speaking, adaptation research has been prone to seek either efficient incremental solutions within current limits, or to advance systemic critique leading to calls for transformation. The example of Flagler Beach however shows how these can be combined to inform a strategy for advocating for social change. This involves not only incremental solutions or calls for grand transformation, but explicitly identifying how incremental adaptation activities can enhance collective agency for achieving more transformative adaptations. This study thus advances scholarship on limits to adaptation beyond the diagnosis of barriers to action (e.g., Moser and Ekstrom 2010) by taking steps towards developing context-specific political strategies for overcoming these barriers.

The issues in Flagler Beach discussed here point to more general problems faced by many other communities in need of timely adaptation, in Florida and around the globe. We have here focused primarily on the structural barriers stemming from problematic governance arrangements. However, it is also clear that overcoming these structural barriers through collective action relies ultimately on adequate levels of social acceptance of the need for adaptation. In the USA, the troubling trend is that the coastal states most vulnerable to the impacts of $\mathrm{CC}$ are also governed by political parties prone to deny the significance (even existence) of CC (Muro et al. 2019). Florida's state government in particular continues to be dominated by climate-skeptical Republican governors and legislators that have long prioritized economic growth over sound environmental policy. This is despite the fact that Florida is set to incur significantly more loss and damage from CC than practically any other state (Muro et al. 2019; Hinkel et al. 2014). In addition to structural constraints, overcoming barriers to adaptation will thus likely require explicit and careful attention to place specific cultural barriers as well (Adger et al. 2013). Some researchers have suggested that the tangible impacts of CC may force changes in public perception and politics (Muro et al. 2019). However, the closing window of opportunity for avoiding the worst $\mathrm{CC}$ scenarios suggests that such a wait-and-see strategy could be counterproductive (United Nations Environment Programme 2019). Indeed, the manifestation of loss and damage from CC is itself indicative of a wider societal failure to maintain a sustainable development. The issue at stake, then, is more than adaptation to CC. It is fundamentally about what kind of development pathways societies will follow into the future (including, e.g., pursuing sustainable energy, agricultural, and transport policies) and whether such a pathway will work to exacerbate or alleviate existing problems of social inequality and environmental deterioration.

Around the world, there are emerging collective movements specifically aimed at addressing CC, often sparked by frustration with the lack of institutional support for needed climate action (see, e.g., Nulman 2016). The absence of serious engagement with the climate question 
by governments and private industry necessitates collective effort in civil society to instigate institutional and policy changes that support effective and equitable action to mitigate, adapt, and recover from the impacts of a warming world. Much more attention in CC research to what constitutes effective strategies for social movements and other forms of civil society organization, and what may impede these actions, is needed. There is also an urgent need to support platforms that facilitate meaningful interactions between scientists and the growing social movements for addressing climate change (Isgren et al. 2019). With this context in mind, we hope that our research proves helpful in the pursuit of effective strategies for addressing the unfolding climate crisis.

Acknowledgements Open access funding provided by Lund University. This research was support by the Swedish Research Council FORMAS. We also thank three anonymous reviews for their very helpful comments and suggesions.

Open Access This article is distributed under the terms of the Creative Commons Attribution 4.0 International License (http://creativecommons.org/licenses/by/4.0/), which permits unrestricted use, distribution, and reproduction in any medium, provided you give appropriate credit to the original author(s) and the source, provide a link to the Creative Commons license, and indicate if changes were made.

\section{References}

Adger WN, Dessai S, Goulden M, Hulme M, Lorenzoni I, Nelson DR, Naess LO, Wolf J, Wreford A (2009) Are there social limits to adaptation to climate change? Clim Chang 93:335-354

Adger WN, Barnett J, Brown K, Marshall N, O’Brien K (2013) Cultural dimensions of climate change impacts and adaptation. Nat Clim Chang 3:112

Alvesson M, Sköldberg K (2017) Reflexive methodology: new vistas for qualitative research. Sage

Amundsen H, Berglund F, Westskog H (2010) Overcoming barriers to climate change adaptation-a question of multilevel governance? Environ Plan C Gov Policy 28:276-289

Anderson D (2017) Green dunes project taking root in Flagler Beach. The Daytona Beach News-Journal

Bassett TJ, Fogelman C (2013) Déjà vu or something new? The adaptation concept in the climate change literature. Geoforum 48:42-53

Beach Management Ad Hoc Committee (2014) City of Flagler Beach beach management plan

Berrang-Ford L, Ford JD, Paterson J (2011) Are we adapting to climate change? Glob Environ Chang 21:25-33

Boda CS (2015) Power and rationality in coastal planning: effects on participation and possibility in the management of barrier island dunes in Flagler Beach, Florida, USA. J Coast Conserv 19:561-576

Boda CS (2017a) The politics of landscape production in the history of development along Florida's Atlantic coast. Landsc Res 42:361-374

Boda CS (2017b) Why a seawall in Flagler Beach could harm sea turtles and violate the law. FlaglerLive.com, January 6

Boda CS (2018a) The beach beneath the road: sustainable coastal development beyond governance and economics. Doctoral Dissertation, Lund University

Boda CS (2018b) Community as a key word: a heuristic for action-oriented sustainability research. Sustainability $10: 2775$

Boda CS (2018c) The entrepreneurial sunshine state: neoliberalism, growth management and environmental conservation in Florida. J Urban Aff 40:838-862

Boda CS (2018d) From economic choice to social choice in coastal management: a critical assessment of the use of cost-benefit analysis in the evaluation of an erosion control project in Flagler County, Florida, USA. Ocean Coast Manag 162:85-99

Boda CS (2019) Seawalls and the tyranny of small decisions. FlaglerLive.com, April 11

Boda CS, Faran T (2018) Paradigm found? Immanent critique to tackle Interdisciplinarity and normativity in science for sustainable development. Sustainability 10:3805

Brody SD, Highfield WE (2005) Does planning work?: testing the implementation of local environmental planning in Florida. J Am Plan Assoc 71:159-175

Cooper J, McKenna J (2008) Social justice in coastal erosion management: the temporal and spatial dimensions. Geoforum 39:294-306

Della Porta D, Diani M (2015) The Oxford handbook of social movements. Oxford University Press 
Dodman D, Mitlin D (2013) Challenges for community-based adaptation: discovering the potential for transformation. J Int Dev 25:640-659

Ehler CN, Basta DJ (1993) Integrated management of coastal areas and marine sanctuaries: a new paradigm. Oceanus 36:6-14

Feagin RA, Smith WK, Psuty NP, Young DR, Martínez ML, Carter GA, Lucas KL, Gibeaut JC, Gemma JN, Koske RE (2010) Barrier islands: coupling anthropogenic stability with ecological sustainability. J Coast Res 26:987-992

Feola GJA (2015) Societal transformation in response to global environmental change: a review of emerging concepts. Ambio. 44:376-390

Field CB, Barros V, Stocker TF, Dahe Q (2012) Managing the risks of extreme events and disasters to advance climate change adaptation: special report of the intergovernmental panel on climate change. Cambridge University Press

FlaglerLive (2012) Attorney general OK's Flagler Beach's plan to spend sales tax money on erosion projects. FlaglerLive, June 7

FlaglerLive (2016a) 150 volunteers swarm to clean up Flagler's beaches, some to reopen by mid-week; FPC students clear Graham Swamp FlaglerLive.com, October 16

FlaglerLive (2016b) County tallies up almost $\$ 60$ million cost of repairing beaches but lacks comprehensive plan. FlaglerLive.com, December 19

FlaglerLive (2016c) Hurricanes Matthew and Hermine damage reach $\$ 1.59$ billion, A1A a big bite. FlaglerLive. com, December 16

FlaglerLive (2016d) New A1A options include moving it to central and Daytona avenues, and 52-mile sea wall FlaglerLive.com, December 15

FlaglerLive (2017a) Flagler depleted as 2017 hurricane season begins; tax holiday this weekend on emergency supplies. FlaglerLive.com, June 1

FlaglerLive (2017b) From mosquito control to National Guard, hurricane costs taking a toll on budgets FlaglerLive.com, October 13

FlaglerLive (2017c) Progressive voices rise to resist locally as Flagler Beach "rally by the sea" rebukes Trumpism. FlaglerLive.com. April 29

FlaglerLive (2018a) \$22.4 million A1A rebuilding and sea wall construction in Flagler Beach starts in January. FlaglerLive.com, November 30

FlaglerLive (2018b) Flagler Beach restores beach management panel in hopes of securing $\$ 500,000$ a year. FlaglerLive.com, June 14

Florida Department of Environmental Protection (2019) Critically eroded beaches in Florida. Engineering, hydrology and geology program, Division of Water Resources Management

Gifford R (2011) The dragons of inaction: psychological barriers that limit climate change mitigation and adaptation. Am Psychol 66:290

Gittman RK, Fodrie FJ, Popowich AM, Keller DA, Bruno JF, Currin CA, Peterson CH, Piehler MF (2015) Engineering away our natural defenses: an analysis of shoreline hardening in the US. Front Ecol Environ 13: 301-307

Guy WE (1983) Florida's coastal management program: a critical analysis. Coast Manag 11:219-248

Hägerstrand T (2001) A look at the political geography of environmental management. Sustainable Landscapes and Lifeways Scale and Appropriateness, 35-58

Hägerstrand T, Clark E (1998) On the political geography of transportation and land use policy coordination. COST 332: transport and land-use policies: resistance and hopes for coordination: proceedings of the Launching Seminar of the Action COST 332 24-25 October 1996, Barcelona, Spain. Office for Official Publications of the European Communities, 19

Hinkel J, Lincke D, Vafeidis AT, Perrette M, Nicholls RJ, Tol RSJ, Marzeion B, Fettweis X, Ionescu C, Levermann A (2014) Coastal flood damage and adaptation costs under 21st century sea-level rise. Proc Natl Acad Sci 111(9):3292-3297

Isgren E, Boda C, Harnesk D, O'byrne D (2019) Science has much to offer social movements in the face of planetary emergencies. Nat Ecol Evol 3:1498

Khan MR, Roberts JT (2013) Adaptation and international climate policy. Wiley Interdiscip Rev Clim Chang 4: $171-189$

Kousky C (2014) Managing shoreline retreat: a US perspective. Clim Chang 124:9-20

Macmanus SA, Watson TA, Quecan AF (2008) The economics and politics of financing Florida's many governments. In: Benton JE (ed) Government and politics in Florida, 3rd edn. University Press of Florida, Gainesville

Magnan A, Schipper E, Burkett M, Bharwani S, Burton I, Eriksen S, Gemenne F, Schaar J, Ziervogel G (2016) Addressing the risk of maladaptation to climate change. Wiley Interdiscip Rev Clim Chang 7:646-665 
Mahoney J, Thelen K (2009) Explaining institutional change: ambiguity, agency, and power. Cambridge University Press

Masson-Delmotte V, Zhai P, Pörtner H, Roberts D, Skea J, Shukla P, Waterfield T (2018) Global warming of 1.5 C. an IPCC special report on the impacts of global warming of $1.5 \mathrm{C}$ above pre-industrial levels and related global greenhouse gas emission pathways, in the context of strengthening the global response to the threat of climate change, sustainable development, and efforts to eradicate poverty. World Meteorological Organization

McAlevey J (2016) No shortcuts: organizing for power in the new gilded age. Oxford University Press

McGuire CJ (2018) Examining legal and regulatory barriers to climate change adaptation in the coastal zone of the United States. Cogent Environ Sci 4:1-11

Measham TG, Preston BL, Smith TF, Brooke C, Gorddard R, Withycombe G, Morrison C (2011) Adapting to climate change through local municipal planning: barriers and challenges. Mitig Adapt Strateg Glob Chang 16:889-909

Moser SC, Ekstrom JA (2010) A framework to diagnose barriers to climate change adaptation. Proc Natl Acad Sci: 201007887

Murawski SA (2007) Ten myths concerning ecosystem approaches to marine resource management. Mar Policy 31:681-690

Muro M, Victor DG, Whiton J (2019) How the geography of climate damage could make the politics less polarizing. Online: The Brookings Institute

Nicholas JC, Chapin TS, Chapin T, Connerly C, Higgins H (2007) The fiscal theory and reality of growth management in Florida. Growth management in Florida: Planning for paradise, 51-66

Noble IRHS, Anokhin YA, Carmin J, Goudou D, Lansigan FP, Osman-Elasha B, Villamizar A (2014) Adaptation needs and options. In: Field CB et al (eds) Climate change 2014: impacts, adaptation, and vulnerability. Contribution of working group II to the fifth assessment report of the intergovernmental panel of climate change. Cambridge University Press, Cambridge; New York

Nulman E (2016) Climate change and social movements: civil society and the development of national climate change policy. Springer

Oost A, Hoekstra P, Wiersma A, Flemming B, Lammerts E, Pejrup M, Hofstede J, Van der Valk B, Kiden P, Bartholdy J (2012) Barrier island management: lessons from the past and directions for the future. Ocean Coast Manag 68:18-38

Pachauri RK, Allen M, Barros V, Broome J, Cramer W, Christ R, Church J, Clarke L, Dahe Q, Dasgupta P (2014) Climate change 2014: synthesis report. Contribution of working groups I, II and III to the fifth assessment report of the Intergovernmental Panel on Climate Change

Park S, Marshall NA, Jakku E, Dowd A-M, Howden SM, Mendham E, Fleming A (2012) Informing adaptation responses to climate change through theories of transformation. Glob Environ Chang 22:115-126

Parry M, Parry ML, Canziani O, Palutikof J, VAN DER Linden P, Hanson C (2007) Climate change 2007impacts, adaptation and vulnerability: working group II contribution to the fourth assessment report of the IPCC. Cambridge University Press

Pelham TG (2007) A historical perspective for evaluating Florida's evolving growth management process. Growth management in Florida: Planning for paradise, 7-17

Pelling M (2010) Adaptation to climate change: from resilience to transformation. Routledge

Pelling M, Manuel-Navarrete D (2011) From resilience to transformation: the adaptive cycle in two Mexican urban centers. Ecol Soc 16

Purcell M, Brown JC (2005) Against the local trap: scale and the study of environment and development. Prog Dev Stud 5(4):279-297

Ribot J (2011) Vulnerability before adaptation: toward transformative climate action. Glob Environ Chang 4: $1160-1162$

Runhaar H, Wilk B, Persson Å, Uittenbroek C, Wamsler C (2018) Mainstreaming climate adaptation: taking stock about "what works" from empirical research worldwide. Reg Environ Chang 18:1201-1210

Ryan S (2018) Matthew's coastal bite was 'wake up call' for Flagler Beach residents. The Daytona Beach NewsJournal

Siders AR, Hino M, Mach KJ (2019) The case for strategic and managed climate retreat. Science. 365(6455): $761-768$

Simmons J (2016) Survey shows locals prioritize beach cleanliness, erosion. Palm Coast Observer, Thursday, November 3

Stieb M (2019) Florida GOP regrets 'lost' decade on climate change. Intelligencer. Oct, New Yorker Magazine, p 17

Tarrow SG (2011) Power in movement: social movements and contentious politics. Cambridge University Press 
Termeer CJ, Dewulf A, Biesbroek GR (2017) Transformational change: governance interventions for climate change adaptation from a continuous change perspective. J Environ Plan Manag 60:558-576

Tilly C (1977) Studying social movements/studying collective action. CRSO working paper \#168. Ann Arbor: University of Michigan

Tilly C (2008) Contentious performances. Cambridge University Press Cambridge

Tilly C, Wood LJ (2015) Social movements: 1768-2012. Routledge

Titus JG, Hudgens D, Trescott D, Craghan M, Nuckols W, Hershner C, Kassakian J, Linn C, Merritt P, Mccue T (2009) State and local governments plan for development of most land vulnerable to rising sea level along the US Atlantic coast. Environ Res Lett 4:044008

Tschakert P, Barnett J, Ellis N, Lawrence C, Tuana N, New M, Elrick-Barr C, Pandit R, Pannell D (2017) Climate change and loss, as if people mattered: values, places, and experiences. Wiley Interdiscip Rev Clim Chang 8

United Nations Environment Programme (2019). Emissions Gap Report 2019. UNEP, Nairobi

USGCRP (2018) Impacts, risks, and adaptation in the United States: fourth national climate assessment. In: Reidmiller DR, Avery CW, Easterling DR, Kunkel KE, Lewis KLM, Maycock TK, Stewart BC (eds) . U.S. Global Change Research Program, Washington DC

Vella K, Butler WH, Sipe N, Chapin T, MURLEY (2016) Voluntary collaboration for adaptive governance: the southeast Florida regional climate change compact. J Plan Educ Res 36:363-376

Walker ET (2008) Contingent pathways from joiner to activist: the indirect effect of participation in voluntary associations on civic engagement. Sociol Forum 23:116-143

Warner K, van der Geest K (2013) Loss and damage from climate change: local-level evidence from nine vulnerable countries. Int J Glob Warming 5:367-386

Westley F, Tjornbo O, Schultz L, Olsson P, Folke C, Crona B, Bodin Ö (2013) A theory of transformative agency in linked social-ecological systems. Ecol Soc 18

Publisher's note Springer Nature remains neutral with regard to jurisdictional claims in published maps and institutional affiliations. 